\title{
Feasibility of SBRT for hepatocellular carcinoma in Brazil - a prospective pilot study
}

\author{
Andre Tsin Chih Chen ${ }^{1}$, Fabio Payão ${ }^{2}$, Aline Lopes Chagas $^{3}$, Regiane Saraiva De Souza Melo Alencar ${ }^{3}$, \\ Claudia Megumi Tani ${ }^{3}$, Karina Gondim Moutinho da Conceição Vasconcelos ${ }^{1}$, Manoel de Souza Rocha ${ }^{4}$, \\ Heloisa de Andrade Carvalho ${ }^{5}$, Paulo Marcelo Gehm Hoff ${ }^{6}$, Flair José Carrilho ${ }^{3}$ \\ ${ }^{1}$ Department of Radiation Oncology, Instituto do Cancer do Estado de Sao Paulo, Hospital das Clinicas, \\ Faculdade de Medicina da USP, Sao Paulo, SP, Brazil \\ ${ }^{2}$ Department of Radiology, Instituto do Cancer do Estado de Sao Paulo, Hospital das Clinicas, \\ Faculdade de Medicina da USP, Sao Paulo, SP, Brazil \\ ${ }^{3}$ Department of Gastroenterology, Instituto do Cancer do Estado de Sao Paulo, Hospital das Clinicas, \\ Faculdade de Medicina da USP, Sao Paulo, SP, Brazil \\ ${ }^{4}$ Department of Radiology, Instituto de Radiologia, Hospital das Clinicas, Faculdade de Medicina da USP, Sao Paulo, SP, Brazil \\ ${ }^{5}$ Department of Radiation Oncology, Instituto de Radiologia, Hospital das Clinicas, Faculdade de Medicina da USP, Sao Paulo, SP, Brazil \\ ${ }^{6}$ Department of Clinical Oncology, Instituto do Cancer do Estado de Sao Paulo, Hospital das Clinicas, \\ Faculdade de Medicina da USP, Sao Paulo, SP, Brazil
}

\begin{abstract}
Background: The aim of the study was to evaluate the feasibility and safety of stereotactic body radiotherapy (SBRT) for the treatment of hepatocellular carcinoma in Brazil. SBRT is an evolving treatment in HCC patients not candidates to other local therapies. Its adoption in clinical practice has been heterogeneous, with lack of data on its generalizability in the Brazilian population.
\end{abstract}

Materials and methods: We conducted a prospective pilot study involving HCC patients after failure or ineligibility for transarterial chemoembolization. Patients received SBRT 30 to $50 \mathrm{~Gy}$ in 5 fractions using an isotoxic prescription approach. This study is registered at clinicaltrials.gov NCT02221778.

Results: From Nov 2014 through Aug 2019, 26 patients received SBRT with 40 Gy median dose. Underlying liver disease was hepatitis C, hepatitis B and alcohol-related in, respectively, 50\%, 23\% and 19\% of patients. Median lesion size was $3.8 \mathrm{~cm}$ (range, 1.5-10 cm), and 46\% had multiple lesions. Thirty-two percent had tumor vascular thrombosis; median pretreatment alpha-fetoprotein (AFP) was $171.7 \mathrm{ng} / \mathrm{mL}$ (range, 4.2-5,494 ng/mL). 1y-local progression-free survival (PFS) was $86 \%(95 \% \mathrm{Cl}$ : $61 \%$ to $95 \%$ ), with higher local control in doses $\geq 45 \mathrm{~Gy}(\mathrm{p}=0.037 ; \mathrm{HR}=0.12)$. 1y-liver PFS, distant PFS and OS were, respectively, $52 \%, 77 \%$ and $79 \%$. Objective response was seen in $89 \%$ of patients, with 3 months post-SBRT median AFP of $12 \mathrm{ng} / \mathrm{mL}$ (2.4-637 ng/mL). There were no grade 3 or 4 clinical toxicities. Grade 3 or 4 laboratory toxicities occurred in $27 \%$ of patients. Conclusion: SBRT is feasible and safe in patients unresponsive or ineligible for TACE in Brazil. Our study suggests doses $\geq 45$ Gy yields better local control.

Key words: radiosurgery; stereotactic body radiotherapy; therapeutic chemoembolization; hepatocellular carcinoma; clinical trial

Rep Pract Oncol Radiother 2021;26(2):226-236

Address for correspondence: Andre Tsin Chih Chen, MD, PhD, Av. Dr. Arnaldo, 251 Sao Paulo, SP, Brazil 01246-000;

e-mail: andre.chen@hc.fm.usp.br

This article is available in open access under Creative Common Attribution-Non-Commercial-No Derivatives 4.0 International (CC BY-NC-ND 4.0) license, allowing to download articles and share them with others as long as they credit the authors and the publisher, but without permission to change them in any way or use them commercially 


\section{Introduction}

Hepatocellular carcinoma (HCC) is the $6^{\text {th }}$ most commonly diagnosed cancer and the $4^{\text {th }}$ leading cause of cancer death worldwide [1]. Incidence is close to mortality, highlighting tumor aggressiveness. The majority of cases are diagnosed in developing countries $[1,2]$.

In South America, the majority of patients is diagnosed at late stages, as reflected in Transarterial Chemoembolization (TACE) being the most common treatment for HCC [3]. TACE improves survival mainly in patients without major vascular thrombosis $[4,5]$. However, treatment efficacy is reduced after multiple sessions. TACE should not be repeated when substantial necrosis is not achieved after two rounds of treatment or when follow-up treatment fails to induce noticeable necrosis at sites that have progressed after an initial tumor response [6]. There is paucity of effective local therapies after failure or ineligibility for TACE $[7,8]$.

Stereotactic Body Radiotherapy (SBRT) is an emerging treatment option that uses highly focused radiation in few sessions to treat HCC. Phase I and II studies have shown encouraging results [9-16], but incorporation of SBRT by guidelines has been heterogeneous [6,17-19]. Additionally, developing countries are underrepresented in the published literature of liver SBRT, with most studies coming from Asia, North America and Europe. In 2014, we initiated a prospective pilot study to evaluate the feasibility and safety of SBRT in patients unresponsive or ineligible for TACE in the Brazilian population.

\section{Materials and methods}

This was a single-arm prospective pilot study. Patients were recruited at Instituto do Cancer do Estado de Sao Paulo, an academic tertiary cancer center in Brazil. HCC diagnosis was according to the American Association for the Study of Liver Diseases (AASLD) 2010 guidelines [20]. Before enrolling, patients 1) had received at least two previous sessions of TACE and had remained with a viable tumor or 2) were ineligible for TACE (e.g., tumor vascular thrombosis (TVT), severe post-embolization syndrome, medical comorbidities).

Eligible patients had 1 to 5 HCC lesions with maximum diameter of $10 \mathrm{~cm}$ and no extra-hepatic disease. Uninvolved liver had to be $\geq 700 \mathrm{cc}$ [21], accounting for at least $40 \%$ of total liver volume. All patients had Child-Pugh score A, Eastern Cooperative Oncology Group (ECOG) performance 0 to 1 , hemoglobin $\geq 8 \mathrm{mg} / \mathrm{dL}$, platelets $\geq 45 \times 10^{9} / \mathrm{L}$, neutrophil count $>1.2 \times 10^{9} / \mathrm{L}$, total bilirubin $\leq 2$ $\mathrm{mg} / \mathrm{dL}$, International Normalized Ratio (INR) $<1.7$, alanine aminotransferase (ALT) and aspartate aminotransferase (AST) $<6 \times$ the upper limit of normal (ULN), albumin $>2.8 \mathrm{mg} / \mathrm{dL}$ and serum creatinine $<1.5 \times$ ULN.

Exclusion criteria were previous radiation therapy (RT) to the upper abdomen, clinically detectable ascites, encephalopathy, main or common bile duct involvement, esophageal bleeding in the previous 3 months, large esophageal varices with red color signs or patients with severe gastrointestinal symptoms. Concomitant systemic treatment was not allowed; a minimum interval of 4 weeks from the last systemic treatment was required before enrollment. Patients with other malignant neoplasms were allowed if HCC carried a worse prognosis.

Patients that fulfilled the inclusion criteria and agreed to participate in the study signed written informed consents. The study was conducted in accordance with the ethical guidelines of the Declaration of Helsinki and posterior revisions [22], as reflected in a priori approval by the institutional review committee.

\section{Radiation planning and treatment delivery}

Patients were immobilized using a customized vacuum cushion (body $\mathrm{fix}^{\odot}$ ) and had abdominal compression or Active Breathing $\mathrm{Control}^{\circ}$ to reduce liver motion throughout respiration. Multiphasic Computed Tomography (CT) for radiation planning was acquired in the exhale breath-hold. Additionally, fluoroscopy and four-dimensional CT (4D-CT) were performed to evaluate liver motion.

Gross Tumor Volume (GTV) was defined as 1) arterial-enhancing lesions with washout on venous or delayed phase or 2) washout in venous or delayed phase for infiltrative HCC. To improve target delineation accuracy, diagnostic magnetic resonance imaging (MRI) co-registration was performed as needed. There was no clinical target volume (CTV) expansion $(\mathrm{CTV}=\mathrm{GTV})$. Fluoroscopy and $4 \mathrm{D}-\mathrm{CT}$ information were used to account for tumor mo- 
tion through the respiratory cycle to generate the internal target volume (ITV). A $5 \mathrm{~mm}$ margin was added to the ITV to generate the planning target volume (PTV).

Doses of 30 to 50 Gy in 5 daily fractions were prescribed using an isotoxic approach as proposed by RTOG 1112 [23]. We prescribed the highest dose that could meet the mean liver dose, according to Table S1 (supplementary material online). Planning was performed using Volumetric Modulated Arc Therapy (VMAT). Treatment was delivered in consecutive working days with $6 \mathrm{MV}$ linear accelerator Elekta Axesse ${ }^{\circledast}$. At each treatment fraction, fluoroscopy and CBCT were performed, with 6-degree couch correction and reimaging before treatment. No fiducials were used.

Systemic therapy after SBRT was not standardized in the trial protocol. Patients typically received sorafenib after progression to the trial treatment.

\section{Endpoints}

Our primary endpoint was local progression-free survival (LPFS), measured per modified Response Evaluation Criteria in Solid Tumors (mRECIST) [24] and defined as the absence of increase of 20\% in the sum of all diameters of treated lesions. Preexisting TVT progression was considered local progression. Imaging modality was preferentially CT. MRI was ordered as needed for additional lesion conspicuity. Baseline imaging modality (CT or MRI) was maintained throughout follow-up for consistency.

Secondary endpoints were liver progression-free survival (PFS), defined as absence of new liver lesions or new TVT; distant PFS, defined as the absence of extra-hepatic disease; overall survival (OS) and toxicity measured by the Common Terminology Criteria for Adverse Events (CTCAE) v.4.0. All time-to-event endpoints were measured from the start of SBRT. Patients that received liver transplant were censored for LPFS at the day of transplantation, but remained at-risk for other endpoints.

Patients were followed monthly in the first 3 months and every 3 months thereafter. Liver imaging was performed every 3 months.

\section{Statistical analysis}

This pilot study was planned with a convenience sample size of 25 patients.
Survival was estimated by the method of Kaplan-Meier and compared using the log-rank test. Continuous variables were compared using Wilcoxon rank-sum test. HR were calculated using Cox regression. Statistical significance was set to $\mathrm{p} \leq 0.05$. There were no corrections for multiple comparisons. We used Stata Release 14, College Station, TX for statistical analyses. The study is registered at ClinicalTrials.gov number NCT02221778.

This research did not receive any specific grant from funding agencies in the public, commercial, or not-for-profit sectors.

\section{Results}

From November 2014 through August 2019, twenty-six patients received SBRT and were analyzed. Fig. S1 shows the flow diagram of patients (supplementary material online). Median follow-up for patients alive was 28.5 months (range 6.2-65.7 months). No patient was lost to follow-up.

Table 1 describes patients' characteristics. Median age was 69 years, with eleven (42\%) patients older than 70 years of age. Underlying liver disease was hepatitis C, hepatitis B and alcohol-related, in respectively, $50 \%, 23 \%$ and $19 \%$ of patients. All patients were Child-Pugh score A. Three (12\%) patients received previous hepatectomy, one received RFA and 21 (81\%) patients received previous TACE. Of these, the status after the last TACE was progressive disease in $62 \%$ and stable disease (no response) in $38 \%$ of patients. TVT was present in $7(27 \%)$ patients, and was the main reason of ineligibility for TACE. Median alpha-fetoprotein (AFP) was $171.7 \mathrm{ng} / \mathrm{mL}$ (range 4.2-5,494 ng/mL) and $13(50 \%)$ patients had AFP $>200 \mathrm{ng} / \mathrm{mL}$. Median SBRT prescription dose was 40 Gy (range 30-50 Gy) in 5 fractions.

\section{Local progression-free survival}

LPFS at 1 and 2 years were, respectively, $86 \%$ (95\% CI: 61-95\%) and 64\% (95\% CI: 29-85\%). Median LPFS was 34.7 months (Fig. 1A). Patients that received SBRT dose $\geq \_45$ Gy had a higher chance of local control. Median LPFS for patients that received $\geq 45$ Gy was not reached vs. 12.1 months in patients that received $<45 \mathrm{~Gy}(\mathrm{p}=0.037 ; \mathrm{HR}=0.12$, 95\% CI: 0.01-1.19) (Fig. 1B). Table 2 shows univariate analysis of prognostic factors associated with LPFS, 
Table 1. Patients characteristics

\begin{tabular}{|c|c|c|}
\hline Characteristics & n (\%) & Median (range) \\
\hline Age & & $69(42-80)$ \\
\hline \multicolumn{3}{|l|}{ Gender } \\
\hline Male & $21(81 \%)$ & \\
\hline Female & $5(19 \%)$ & \\
\hline \multicolumn{3}{|l|}{ ECOG } \\
\hline 0 & $18(69 \%)$ & \\
\hline 1 & $8(31 \%)$ & \\
\hline Child A & $26(100 \%)$ & \\
\hline \multicolumn{3}{|l|}{ BCLC Stage } \\
\hline A & $9(35 \%)$ & \\
\hline B & $5(19 \%)$ & \\
\hline $\mathrm{C}$ & $12(46 \%)$ & \\
\hline \multicolumn{3}{|l|}{ Underlying liver disease } \\
\hline Hepatitis B & $6(23 \%)$ & \\
\hline Hepatitis C & $13(50 \%)$ & \\
\hline Alcohol & $5(19 \%)$ & \\
\hline NASH & $2(8 \%)$ & \\
\hline Schistosomiasis mansoni & $1(4 \%)$ & \\
\hline Number of Previous TACE & & $2(0-5)$ \\
\hline 0 & $5(19 \%)$ & \\
\hline 1 & $3(12 \%)$ & \\
\hline 2 & $7(27 \%)$ & \\
\hline 3 & $6(23 \%)$ & \\
\hline 4 & $1(4 \%)$ & \\
\hline 5 & $4(15 \%)$ & \\
\hline Number of lesions & $47(100 \%)$ & $1(1-4)$ \\
\hline Size of largest lesion [cm] & & $3.8(1.5-10)$ \\
\hline Tumor vascular thrombosis & $7(27 \%)$ & \\
\hline Dose [Gy] & & $40(30-50)$ \\
\hline \multicolumn{3}{|l|}{ AFP } \\
\hline$>200 \mathrm{ng} / \mathrm{mL}$ & $13(50 \%)$ & \\
\hline$\leq 200 \mathrm{ng} / \mathrm{mL}$ & $13(50 \%)$ & \\
\hline \multicolumn{3}{|l|}{ Baseline laboratory values } \\
\hline AFP $[\mathrm{ng} / \mathrm{mL}]$ & & $171.7(4.2-5494)$ \\
\hline ALT [U/L] & & $39(7-119)$ \\
\hline AST [U/L] & & $44(10-162)$ \\
\hline ALP [U/L] & & $103(59-246)$ \\
\hline GGT [U/L] & & 109 (19-612) \\
\hline Bilirubin [mg/dL] & & $0.9(0.2-1.9)$ \\
\hline Albumin [g/dL] & & $4.0(3.3-4.8)$ \\
\hline INR & & $1.14(1.00-1.49)$ \\
\hline Creatinin [mg/dL] & & $0.87(0.56-1.32)$ \\
\hline Platelets $\left[\times 10^{9} / \mathrm{L}\right]$ & & $117(52-300)$ \\
\hline
\end{tabular}

ECOG - Eastern Cooperative Oncology Group; BCLC — Barcelona Clinic Liver Cancer Classification; NASH - nonalcoholic steatohepatitis;

TACE — transarterial chemoembolization; Gy — Gray; AFP — alpha-fetoprotein; ALT — alanine aminotransferase; AST — aspartate aminotransferase; ALP — alkaline phosphatase; GGT — gamma-glutamyl transferase; INR — international normalized ratio
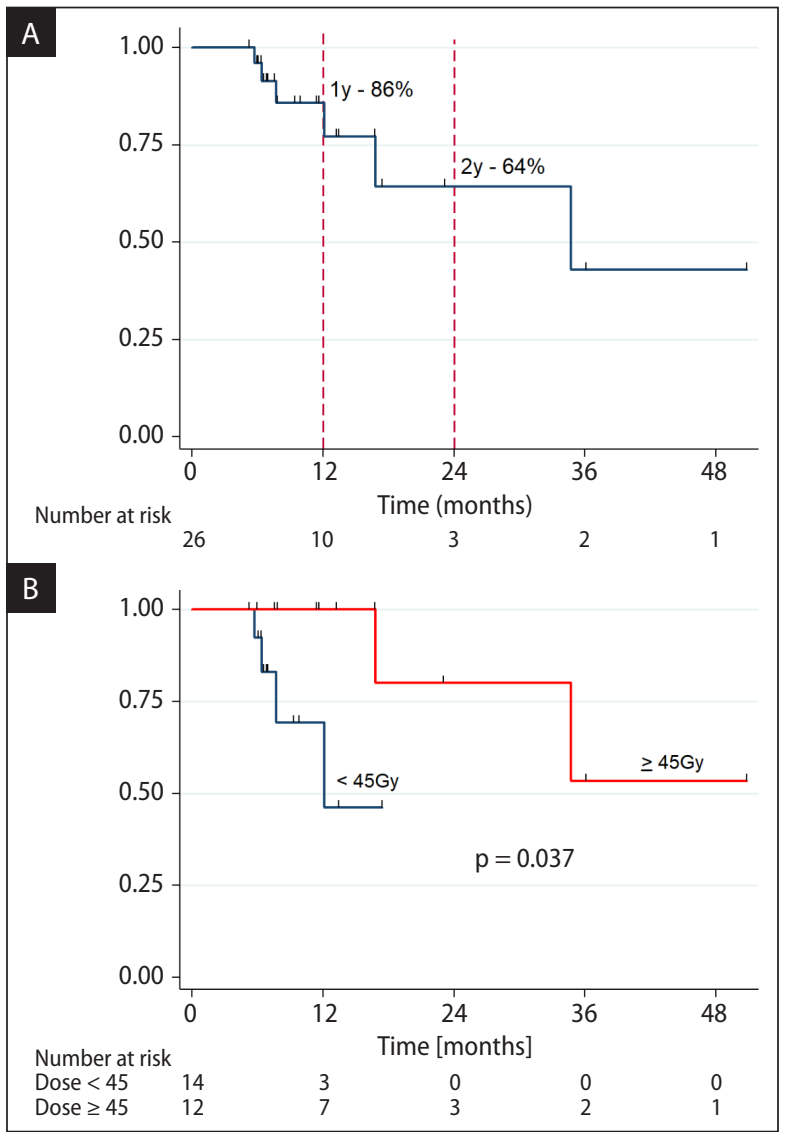

Figure 1. Local progression-free survival. Kaplan-Meier estimates of local progression-free survival (A) All patients. Dashed lines depict 1- and 2-year local progression-free survival of $86 \%$ and $64 \%$ (B) By prescription dose of $45 \mathrm{~Gy}$. Patients receiving dose $\geq 45 \mathrm{~Gy}$ had better local control $(p=0.037$; log-rank test)

liver PFS and OS. Previous TACE had no impact on LPFS ( $\mathrm{p}=0.811$; HR $=0.76,95 \%$ CI: 0.08-6.92).

Liver PFS at 1 and 2 years were, respectively, $52 \%$ (95\% CI: $28-71 \%$ ) and 26\% (95\% CI: 8-48\%) Median Liver PFS was 12.1 months (Fig. 2). Hepatitis C negatively impacted liver PFS, with HR 3.58 (95\% CI: 1.15-11.18; $\mathrm{p}=0.02$ ) (Tab. 2).

Distant PFS at 1 and 2 years were similar at $77 \%$ (95\% CI: 53-90\%). Median distant PFS was not reached.

Median survival was 21 months. OS at 1 and 2 years were, respectively, 79\% (95\% CI: 57-91\%) and 42\% (95\% CI: 22-61\%) (Fig. 3). Higher SBRT dose, presence of TVT, AFP $>200 \mathrm{ng} / \mathrm{mL}$ were not statistically associated with OS, whereas patients with Hepatitis $C$ had worse survival ( $\mathrm{p}=0.046$; $\mathrm{HR}=2.56$; 95\% CI: 0.98-6.67) (Tab. 2). We recommend caution in interpreting these results due to our small sample size. 
Table 2. Univariate analysis of prognostic factors for survival endpoints

\begin{tabular}{|c|c|c|c|}
\hline Prognostic factor & Median (months) & $\mathrm{HR}(95 \% \mathrm{Cl})$ & $\mathbf{p}$ \\
\hline \multicolumn{4}{|c|}{ Local progression-free survival } \\
\hline \multicolumn{4}{|l|}{ Total dose [Gy] } \\
\hline$\geq 45$ & Not reached & $0.12(0.01-1.19)$ & 0.037 \\
\hline$<45$ & 12.1 & & \\
\hline \multicolumn{4}{|l|}{ Hepatitis C } \\
\hline Yes & Not reached & $0.26(0.03-2.25)$ & 0.189 \\
\hline No & 16.8 & & \\
\hline \multicolumn{4}{|c|}{ Tumor vascular thombosis } \\
\hline Yes & Not reached & $2.1(0.39-14.4)$ & 0.326 \\
\hline No & 34.7 & & \\
\hline \multicolumn{4}{|c|}{ Alpha-fetoprotein [ng/mL] } \\
\hline$>200$ & 34.7 & $2.74(0.49-15.20)$ & 0.230 \\
\hline$\leq 200$ & Not reached & & \\
\hline \multicolumn{4}{|l|}{ Number of lesions } \\
\hline 3 or more & Not reached & $0.71(0.08-6.27)$ & 0.758 \\
\hline 1 or 2 & 34.7 & & \\
\hline \multicolumn{4}{|c|}{ Diameter of largest lesion } \\
\hline$>3 \mathrm{~cm}$ & 16.8 & $1.06(0.18-5.91)$ & 0.946 \\
\hline$\leq 3 \mathrm{~cm}$ & 34.7 & & \\
\hline \multicolumn{4}{|l|}{ Previous TACE } \\
\hline Yes & 34.7 & $0.76(0.08-6.92)$ & 0.811 \\
\hline No & Not reached & & \\
\hline \multicolumn{4}{|c|}{ Liver progession-free survival } \\
\hline \multicolumn{4}{|l|}{ Total dose [Gy] } \\
\hline$\geq 45$ & 15.9 & $0.64(0.21-1.92)$ & 0.428 \\
\hline$<45$ & 9.8 & & \\
\hline \multicolumn{4}{|l|}{ Hepatitis C } \\
\hline Yes & 8.9 & $3.58(1.15-11.18)$ & 0.019 \\
\hline No & 15.9 & & \\
\hline \multicolumn{4}{|c|}{ Tumor vascular thombosis } \\
\hline Yes & 8.9 & $1.49(0.46-4.81)$ & 0.492 \\
\hline No & 15.4 & & \\
\hline \multicolumn{4}{|c|}{ Alpha-fetoprotein [ng/mL] } \\
\hline$>200$ & 9.1 & $1.62(0.55-4.73)$ & 0.364 \\
\hline$\leq 200$ & 15.4 & & \\
\hline \multicolumn{4}{|l|}{ Number of lesions } \\
\hline 3 or more & 7.1 & $1.11(0.34-3.58)$ & 0.850 \\
\hline 1 or 2 & 15.4 & & \\
\hline \multicolumn{4}{|c|}{ Diameter of largest lesion } \\
\hline$>3 \mathrm{~cm}$ & 12.1 & $0.69(0.20-2.33)$ & 0.550 \\
\hline$\leq 3 \mathrm{~cm}$ & 9.1 & & \\
\hline \multicolumn{4}{|l|}{ Previous TACE } \\
\hline Yes & 12.1 & $1.19(0.26-5.34)$ & 0.817 \\
\hline No & 9.8 & & \\
\hline
\end{tabular}


Table 2. Univariate analysis of prognostic factors for survival endpoints

\begin{tabular}{|c|c|c|c|}
\hline Prognostic factor & Median (months) & HR $(95 \% \mathrm{CI})$ & p \\
\hline \multicolumn{4}{|c|}{ Overall survival } \\
\hline \multicolumn{4}{|l|}{ Total dose [Gy] } \\
\hline$\geq 45$ & 26.5 & $0.82(0.32-2.11)$ & 0.686 \\
\hline$<45$ & 18.2 & & \\
\hline \multicolumn{4}{|l|}{ Hepatitis C } \\
\hline Yes & 14.3 & $2.56(0.98-6.67)$ & 0.046 \\
\hline No & 26.5 & & \\
\hline \multicolumn{4}{|c|}{ Tumor vascular thombosis } \\
\hline Yes & 17.6 & $1.51(0.56-4.08)$ & 0.408 \\
\hline No & 22.0 & & \\
\hline \multicolumn{4}{|c|}{ Alpha-fetoprotein [ng/mL] } \\
\hline$>200$ & 17.6 & $1.80(0.70-4.64)$ & 0.212 \\
\hline$\leq 200$ & 22.0 & & \\
\hline \multicolumn{4}{|l|}{ Number of lesions } \\
\hline 3 or more & 36.7 & $0.61(0.20-1.88)$ & 0.739 \\
\hline 1 or 2 & 21.0 & & \\
\hline \multicolumn{4}{|c|}{ Diameter of largest lesion } \\
\hline$>3 \mathrm{~cm}$ & 18.2 & $0.85(0.32-2.21)$ & 0.394 \\
\hline$\leq 3 \mathrm{~cm}$ & 24.9 & & \\
\hline \multicolumn{4}{|l|}{ Previous TACE } \\
\hline Yes & 24.9 & $0.36(0.11-1.22)$ & 0.088 \\
\hline No & 17.6 & & \\
\hline
\end{tabular}

TACE — transarterial chemoembolization

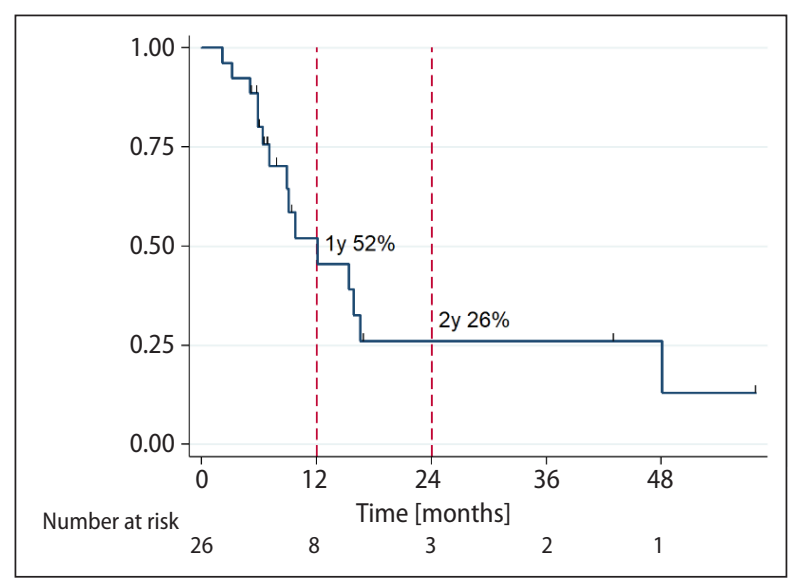

Figure 2. Liver progression-free survival. Kaplan-Meier estimate of liver progression-free survival. Dashed lines depict 1- and 2-year overall survival of, respectively, $52 \%$ and $26 \%$

\section{Toxicity}

Treatment was well tolerated, without treatment-related grade 3 or 4 clinical toxicities. Grade 3 or 4 laboratory toxicities occurred in 7 (27\%)

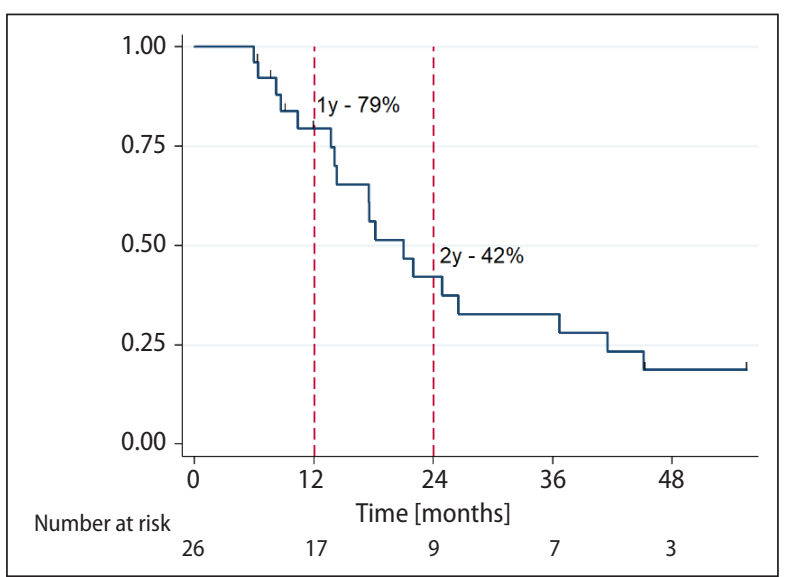

Figure 3. Overall survival. Kaplan-Meier estimate of overall survival. Dashed lines depict 1- and 2-year overall survival of, respectively, $79 \%$ and $42 \%$

patients (Tab. 3). Most of these were transient, occurring 1 to 3 months following treatment and subsiding thereafter. One patient died of progressive liver failure 6 months following treatment. After multidisciplinary team discussion, we considered 
Table 3. Treatment related toxicity

\begin{tabular}{|c|c|c|c|c|}
\hline Toxicity & Grade 1 & Grade 2 & Grade 3 & Grade 4 \\
\hline Clinical & 10 (38\%) & $5(19 \%)$ & $0(0 \%)$ & $0(0 \%)$ \\
\hline Nausea & $5(19 \%)$ & $2(8 \%)$ & $0(0 \%)$ & $0(0 \%)$ \\
\hline Anorexia & $7(27 \%)$ & $0(0 \%)$ & $0(0 \%)$ & $0(0 \%)$ \\
\hline Diarrhea & $3(12 \%)$ & $0(0 \%)$ & $0(0 \%)$ & $0(0 \%)$ \\
\hline Fatigue & $2(8 \%)$ & $1(4 \%)$ & $0(0 \%)$ & $0(0 \%)$ \\
\hline Gastritis & $3(12 \%)$ & $1(4 \%)$ & $0(0 \%)$ & $0(0 \%)$ \\
\hline Dyspepsia & $3(12 \%)$ & $1(4 \%)$ & $0(0 \%)$ & $0(0 \%)$ \\
\hline Chest wall pain & $2(8 \%)$ & $1(4 \%)$ & $0(0 \%)$ & $0(0 \%)$ \\
\hline Rib fracture & $0(0 \%)$ & $1(4 \%)$ & $0(0 \%)$ & $0(0 \%)$ \\
\hline Pneumonitis & $0(0 \%)$ & $1(4 \%)$ & $0(0 \%)$ & $0(0 \%)$ \\
\hline Radiation dermatitis & $1(4 \%)$ & $0(0 \%)$ & $0(0 \%)$ & $0(0 \%)$ \\
\hline Laboratory & $7(27 \%)$ & $12(46 \%)$ & $6(23 \%)$ & $1(4 \%)$ \\
\hline Platelet & $12(46 \%)$ & 8 (31)\%) & $4(15 \%)$ & $0(0 \%)$ \\
\hline Bilirubin & $9(35 \%)$ & $9(35 \%)$ & $1(4 \%)$ & $1(4 \%)$ \\
\hline ALT & 17 (65\%) & $3(12 \%)$ & $0(0 \%)$ & $0(0 \%)$ \\
\hline AST & $14(54 \%)$ & $5(19 \%)$ & $2(8 \%)$ & $0(0 \%)$ \\
\hline ALP & $15(58 \%)$ & $2(8 \%)$ & $0(0 \%)$ & $0(0 \%)$ \\
\hline INR & $13(50 \%)$ & $1(4 \%)$ & $0(0 \%)$ & $0(0 \%)$ \\
\hline Albumin & $6(23 \%)$ & $3(12 \%)$ & $0(0 \%)$ & $0(0 \%)$ \\
\hline
\end{tabular}

Toxicity graded according to the Common Terminology Criteria for Adverse Events v4.0. Data presented as $n$ (\%). ALT — alanine aminotransferase; AST — aspartate aminotransferase; ALP — alkaline phosphatase; INR — international normalized ratio

the death not directly related to SBRT, but possibly related. A detailed discussion of the case can be found online in the supplementary appendix.

\section{Radiologic response}

Eighty-nine percent of patients had objective response per mRECIST, with complete and partial response in, respectively, $54 \%$ and $35 \%$ of patients (Table S2, online). In patients who responded, median time for the best response was 3.7 months (IQR: 3.1-6.8 months; range 2-12.6 months). Figure 4 shows the case of an 80 -year-old woman with hepatitis $\mathrm{B}$ and a single $4 \mathrm{~cm}$ HCC lesion that was treated to $45 \mathrm{~Gy}$. The lesion responded continuously until reaching complete response per mRECIST at 12.6 months. Following complete response, the non-enhancing lesion continued to reduce until 31 months.

\section{Alpha-fetoprotein}

Median pretreatment AFP was $171 \mathrm{ng} / \mathrm{mL}$ (IQR: $12-868 \mathrm{ng} / \mathrm{mL}) ; 3$ months after SBRT, median AFP reduced to $12 \mathrm{ng} / \mathrm{mL}$ (IQR: $6.3-85.6 \mathrm{ng} / \mathrm{mL}$ ) ( $\mathrm{p}=0.003$; Wilcoxon signed-rank test for paired samples) (Fig. S2, Supplementary File). Before treatment, 21 (81\%) patients had AFP above ULN $(>10 \mathrm{ng} / \mathrm{mL}$ ). For these, AFP was a good marker of response.

\section{Discussion}

To the best of our knowledge, no prospective data has been reported using SBRT to treat HCC in Latin America. Our findings indicate the technique is feasible in a Brazilian referral cancer center.

Our study suggests that SBRT has substantial activity against HCC in our patient population. We achieved 1-year LPFS of $86 \%$ in a sample of previously treated patients, with median lesion size of $3.8 \mathrm{~cm}$, AFP > $200 \mathrm{ng} / \mathrm{mL}$ in $50 \%$ and TVT in $27 \%$ of patients. Objective response was seen in $88 \%$ of patients, with $54 \%$ achieving complete response during follow-up. Patients that received SBRT dose $\geq 45$ Gy had a significant longer LPFS.

Other prospective SBRT trials treating HCC-only have reported similar results, with Bujold et al. reporting local control at 1 year of $87 \%$ [11] and Andolino et al. with local control at 2 years of $90 \%$ 


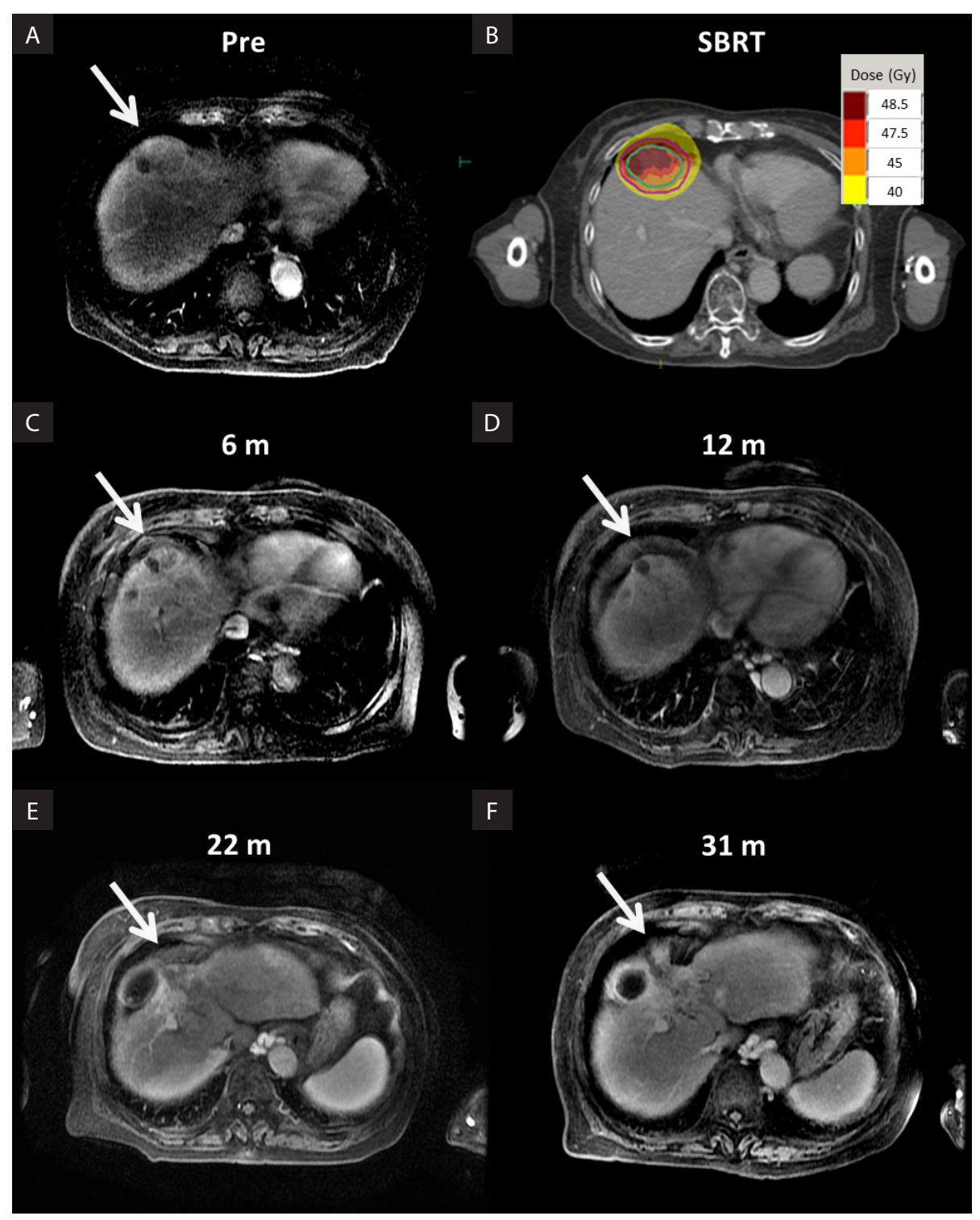

Figure 4. Complete response after stereotactic body radiotherapy (SBRT). Images of an 80-year-old patient who underwent SBRT with $45 \mathrm{~Gy}$ to a single $4 \mathrm{~cm}$ lesion (white arrow). A. Pre-treatment magnetic resonance imaging (MRI); B. SBRT isodose curves. C-F. Follow-up MRIs showing continuous reduction of the treated lesion. In images (C) and (D), transient alterations due to lower isodoses are seen in surrounding liver parenchyma. In images (E) and (F), the gallbladder, with its characteristic homogeneous contrast enhancement, is seen to the right of the arrow. Images are not at the same level due to changes in liver size and shape

[10]. A recent meta-analysis from thirty-two prospective and retrospective studies involving 1950 HCC patients reported pooled 1- and 2-year local control rates of $85.7 \%$ (95\% CI: 80.1-90.0) and $83.6 \%(77.4-88.3)$ [25]. Taken together, these results suggest SBRT is an adequate strategy for HCC not candidate to other therapies. This strategy could be further explored in elderly and frail patients that carry a greater risk to invasive procedures [26].

It is of note that LPFS was similar between patients that received TACE and patients that did not receive it due to ineligibility. Although upfront SBRT is feasible in localized HCC prior to TACE, the clinical benefit of such approach is currently under investigation [27].

In our study, radiologic and laboratory response were not immediate, requiring at least 3 months for initial evaluation. Our median time for the best radiological response was 3.7 months, with patients achieving complete response up to one year after treatment. After RT, cancer cells undergo reproductive death, that is, loss of capacity to reproduce in- 
definitely [28]. A cell may still be physically intact, may be able to make proteins or synthesize DNA, but it has lost its reproductive integrity. Most cells will die while attempting to divide (mitotic death), while some will die by apoptosis [28]. Therefore, after SBRT, from a radiobiological standpoint, the presence of early arterial enhancement with early "washout" should not be considered a sign of viability. Until there is no volume progression, lesions should be considered controlled [10, 11, 29, 30]. Such an approach differs from TACE or radiofrequency ablation and highlights the need to understand RT mechanisms of action to interpret follow-up images.

The possibility of treating TVT with SBRT expands treatment strategies to this group of patients that is usually not candidate to local therapy. In our study, median survival for patients with TVT was 17.6 months. Yoon et al. conducted a randomized study comparing TACE plus conformal RT vs sorafenib in patients with TVT and absence of distant metastases [31]. Among 90 patients enrolled, $79 \%$ had multiple lesions, with median size of the largest lesion of $9.7 \mathrm{~cm}$. TACE + RT had longer time to progression (4.2 months vs. 2.8 months; $\mathrm{p}<0.001)$ and median survival (13.1 months $v s$. 10.2 months; $p=0.04)$. In our opinion, current evidence suggests that RT is an adequate local treatment even in the context of TVT.

Despite our good local control, failure in the remaining liver continues to be a problem. As reported by Takeda et al. [14], this was our main pattern of failure. In our exploratory analysis, baseline hepatitis $\mathrm{C}$ was associated with progression in the untreated liver.

Our median survival of 21 months is within the range of previously prospective studies using SBRT [9-14]. Survival is highly influenced by patient's baseline characteristics. For instance, Bujold et al., in a sample with a median tumor size of $7.2 \mathrm{~cm}$, $55 \%$ TVT and $12 \%$ extra-hepatic disease, reported median survival of 17 months [11]. Andolino et al. studied SBRT in a more favorable population, with single lesion in $85 \%$ of patients, no TVT, median lesion size of $3 \mathrm{~cm}$ and $10 \%$ prior therapy. The authors reported a median survival of 44 months [10].

In comparison with systemic therapy, the SHARP study [32] reported median survival of 10.7 months in a sample with $36 \%$ of TVT and $53 \%$ of extra-hepatic disease. The Asia Pacific study [33] reported median survival of 6.5 months in a sample with $36 \%$ of TVT and $69 \%$ of extra-hepatic disease. Recognizing the tremendous limitations of comparisons across studies, survival of SBRT trials compare favorably to sorafenib.

Toxicity was acceptable in our study, with no grade 3 or 4 clinical toxicities. One death was possibly related to treatment and is within the previously reported range of up to $6.9 \%$ [11].

Our study has several limitations. First, it's a prospective pilot study with a small sample size. Our accrual period was long and reflect the nature of salvage treatment in a complex disease. After failure or ineligibility for TACE, a significant proportion of patients had a worsening liver function or had tumors beyond the inclusion criteria of our trial. Our study generates hypothesis and highlights the importance of conducting worldwide representative phase III trials to definitely establish the role of SBRT in the treatment of HCC.

There are two ongoing phase III randomized trials of SBRT in HCC. IAEA E33036 [27] is comparing TACE vs SBRT in the setting of unresectable HCC unsuitable for conventional ablative therapies. RTOG 1112 [23] is currently testing the suggested benefit of adding SBRT to sorafenib for locally advanced HCC.

\section{Conclusion}

In conclusion, SBRT is feasible in our Brazilian population. Our study suggests that higher SBRT dose improves local progression-free survival with acceptable toxicity. It should be considered as a treatment option in HCC patients unresponsive or ineligible for TACE, before referral to systemic therapy.

\section{Conflict of interest}

None declared.

\section{Funding}

This research did not receive any specific grant from funding agencies in the public, commercial, or not-for-profit sectors.

\section{References}

1. Bray F, Ferlay J, Soerjomataram I, et al. Global cancer statistics 2018: GLOBOCAN estimates of incidence and mortality worldwide for 36 cancers in 185 countries. 
CA Cancer J Clin. 2018; 68(6): 394-424, doi: 10.3322/ caac.21492, indexed in Pubmed: 30207593.

2. Ferlay J, Soerjomataram I, Dikshit R, et al. Cancer incidence and mortality worldwide: sources, methods and major patterns in GLOBOCAN 2012. Int J Cancer. 2015; 136(5): E359-E386, doi: 10.1002/ijc.29210, indexed in Pubmed: 25220842.

3. Debes JD, Chan AJ, Balderramo D, et al. Hepatocellular carcinoma in South America: Evaluation of risk factors, demographics and therapy. Liver Int. 2018; 38(1): 136-143, doi: 10.1111/liv.13502, indexed in Pubmed: 28640517.

4. Llovet JM, Bruix J. Systematic review of randomized trials for unresectable hepatocellular carcinoma: Chemoembolization improves survival. Hepatology. 2003; 37(2): 429-442, doi: 10.1053/jhep.2003.50047, indexed in Pubmed: 12540794.

5. Oliveri RS, Wetterslev J, Gluud C. Transarterial (chemo) embolisation for unresectable hepatocellular carcinoma. Cochrane Database Syst Rev. 2011(3): CD004787, doi: $10.1002 / 14651858 . C D 004787 . p u b 2$, indexed in Pubmed: 21412886.

6. Forner A, Reig M, Bruix J. Hepatocellular carcinoma. Lancet. 2018; 391(10127): 1301-1314, doi: 10.1016/S01406736(18)30010-2, indexed in Pubmed: 29307467.

7. Chow PKH, Gandhi M, Tan SB, et al. Asia-Pacific HepatocelIular Carcinoma Trials Group. SIRveNIB: Selective Internal Radiation Therapy Versus Sorafenib in Asia-Pacific Patients With Hepatocellular Carcinoma. J Clin Oncol. 2018; 36(19): 1913-1921, doi: 10.1200/JCO.2017.76.0892, indexed in Pubmed: 29498924.

8. Vilgrain V, Pereira H, Assenat E, et al. SARAH Trial Group. Efficacy and safety of selective internal radiotherapy with yttrium-90 resin microspheres compared with sorafenib in locally advanced and inoperable hepatocellular carcinoma (SARAH): an open-label randomised controlled phase 3 trial. Lancet Oncol. 2017; 18(12): 1624-1636, doi: 10.1016/S1470-2045(17)30683-6, indexed in Pubmed: 29107679.

9. Cárdenes HR, Price TR, Perkins SM, et al. Phase I feasibility trial of stereotactic body radiation therapy for primary hepatocellular carcinoma. Clin Transl Oncol. 2010; 12(3): 218-225, doi: 10.1007/s12094-010-0492-x, indexed in Pubmed: 20231127.

10. Andolino DL, Johnson CS, Maluccio M, et al. Stereotactic body radiotherapy for primary hepatocellular carcinoma. Int J Radiat Oncol Biol Phys. 2011; 81(4): e447-e453, doi: 10.1016/j.ijrobp.2011.04.011, indexed in Pubmed: 21645977.

11. Bujold A, Massey CA, Kim JJ, et al. Sequential phase I and II trials of stereotactic body radiotherapy for locally advanced hepatocellular carcinoma. J Clin Oncol. 2013; 31(13): 1631-1639, doi: 10.1200/JCO.2012.44.1659, indexed in Pubmed: 23547075.

12. Kang JK, Kim MS, Cho CK, et al. Stereotactic body radiation therapy for inoperable hepatocellular carcinoma as a local salvage treatment after incomplete transarterial chemoembolization. Cancer. 2012; 118(21): 5424-5431, doi: 10.1002/cncr.27533, indexed in Pubmed: 22570179.

13. Scorsetti $M$, Comito $T$, Cozzi $L$, et al. The challenge of inoperable hepatocellular carcinoma (HCC): results of a single-institutional experience on stereotactic body radiation therapy (SBRT). J Cancer Res Clin Oncol. 2015; 141(7):
1301-1309, doi: 10.1007/s00432-015-1929-y, indexed in Pubmed: 25644863.

14. Takeda A, Sanuki N, Tsurugai Y, et al. Phase 2 study of stereotactic body radiotherapy and optional transarterial chemoembolization for solitary hepatocellular carcinoma not amenable to resection and radiofrequency ablation. Cancer. 2016; 122(13): 2041-2049, doi: 10.1002/ cncr.30008, indexed in Pubmed: 27062278.

15. Lasley FD, Mannina EM, Johnson CS, et al. Treatment variables related to liver toxicity in patients with hepatocellular carcinoma, Child-Pugh class A and B enrolled in a phase 1-2 trial of stereotactic body radiation therapy. Pract Radiat Oncol. 2015; 5(5): e443-e449, doi: 10.1016/j. prro.2015.02.007, indexed in Pubmed: 25899219.

16. Durand-Labrunie J, Baumann AS, Ayav A, et al. Curative Irradiation Treatment of Hepatocellular Carcinoma: A Multicenter Phase 2 Trial. Int J Radiat Oncol Biol Phys. 2020; 107(1): 116-125, doi: 10.1016/j.ijrobp.2019.12.004, indexed in Pubmed: 32001057.

17. NCCN Clinical Practice Guidelines in Oncology. Hepatobiliary cancers. NCCN , $2020: 152$.

18. Heimbach JK, Kulik LM, Finn RS, et al. AASLD guidelines for the treatment of hepatocellular carcinoma. Hepatology. 2018;67(1): 358-380, doi: 10.1002/hep.29086, indexed in Pubmed: 28130846.

19. Vogel A, Cervantes A, Chau l, et al. ESMO Guidelines Committee. Hepatocellular carcinoma: ESMO Clinical Practice Guidelines for diagnosis, treatment and follow-up. Ann Oncol. 2018; 29(Suppl 4): iv238-iv255, doi: 10.1093/annonc/mdy308, indexed in Pubmed: 30285213.

20. Bruix J, Sherman M. American Association for the Study of Liver Diseases. Management of hepatocellular carcinoma: an update. Hepatology. 2011; 53(3): 1020-1022, doi: 10.1002/hep.24199, indexed in Pubmed: 21374666.

21. Wang PM, Chung NN, Hsu WC, et al. Stereotactic body radiation therapy in hepatocellular carcinoma: Optimal treatment strategies based on liver segmentation and functional hepatic reserve. Rep Pract Oncol Radiother. 2015; 20(6): 417-424, doi: 10.1016/j.rpor.2015.03.005, indexed in Pubmed: 26696781.

22. World Medical Association. World Medical Association Declaration of Helsinki. JAMA. 2013; 310(20): 2191, doi: 10.1001/jama.2013.281053, indexed in Pubmed: 24141714.

23. Dawson LA, Anderson UMD. Radiation Therapy Oncology Group Rtog 1112 Randomized Phase III Study of Sorafenib Versus Stereotactic Body Radiation Therapy Followed By Sorafenib in Hepatocellular Randomized Phase lii Study of Sorafenib Versus Stereotactic Body Radiation Therapy Follow. Published 2014. https://www.rtog.org/ClinicalTrials/ProtocolTable.aspx..

24. Lencioni R, Llovet JM. Modified RECIST (mRECIST) assessment for hepatocellular carcinoma. Semin Liver Dis. 2010; 30(1): 52-60, doi: 10.1055/s-0030-1247132, indexed in Pubmed: 20175033.

25. Rim CH, Kim HJu, Seong J. Clinical feasibility and efficacy of stereotactic body radiotherapy for hepatocellular carcinoma: A systematic review and meta-analysis of observational studies. Radiother Oncol. 2019; 131: 135-144, doi: 10.1016/j.radonc.2018.12.005, indexed in Pubmed: 30773180.

26. Timmerman R, Paulus R, Galvin J, et al. Excessive toxicity when treating central tumors in a phase II study of 
stereotactic body radiation therapy for medically inoperable early-stage lung cancer. J Clin Oncol. 2006; 24(30): 4833-4839, doi: 10.1200/JCO.2006.07.5937, indexed in Pubmed: 17050868.

27. International Atomic Energy Agency. Randomized Phase III Clinical Trial of Stereotactic Body Radiation Therapy versus Transarterial Chemoembolization in Hepatocellular Carcinoma. https://www.iaea.org/projects/crp/ e33036 (01.2020).

28. Hall EJ. Radiobiology for the Radiologist. 7th ed. Lippincottt Williams \& Wilkins, Philadelphia 2011.

29. Hong TS, Wo JY, Yeap BY, et al. Multi-Institutional Phase Il Study of High-Dose Hypofractionated Proton Beam Therapy in Patients With Localized, Unresectable Hepatocellular Carcinoma and Intrahepatic Cholangiocarcinoma. J Clin Oncol. 2016; 34(5): 460-468, doi: 10.1200/ JCO.2015.64.2710, indexed in Pubmed: 26668346.

30. Tétreau R, Llacer C, Riou O, et al. Evaluation of response after SBRT for liver tumors. Rep Pract Oncol Radiother.
2017; 22(2): 170-175, doi: 10.1016/j.rpor.2015.12.004, indexed in Pubmed: 28490989.

31. Yoon SM, Ryoo BY, Lee SoJ, et al. Efficacy and Safety of Transarterial Chemoembolization Plus External Beam Radiotherapy vs Sorafenib in Hepatocellular Carcinoma With Macroscopic Vascular Invasion: A Randomized Clinical Trial. JAMA Oncol. 2018; 4(5): 661-669, doi: 10.1001/jamaoncol.2017.5847, indexed in Pubmed: 29543938.

32. Llovet JM, Ricci S, Mazzaferro V, et al. SHARP Investigators Study Group. Sorafenib in advanced hepatocellular carcinoma. N Engl J Med. 2008; 359(4): 378-390, doi: 10.1056/ NEJMoa0708857, indexed in Pubmed: 18650514.

33. Cheng AL, Kang YK, Chen Z, et al. Efficacy and safety of sorafenib in patients in the Asia-Pacific region with advanced hepatocellular carcinoma: a phase III randomised, double-blind, placebo-controlled trial. Lancet Oncol. 2009; 10(1): 25-34, doi: 10.1016/S1470-2045(08)70285-7, indexed in Pubmed: 19095497. 